\title{
FAKTOR MANUSIA DAN FAKTOR PEKERJAAN YANG BERHUBUNGAN DENGAN KECELAKAAN KERJA PT XY TAHUN 2016
}

\author{
Human Factors and Factors Related to Work Accidents PT XY 2016 \\ Herdianti $^{1 *}$, Hamdani ${ }^{2}$ \\ ${ }^{1}$ Program Studi Kesehatan Lingkungan, STIKES Ibnu Sina, Batam \\ *(herdiantinyup@gmail.com) \\ ${ }^{2}$ Program Studi Kesehatan Masyarakat, STIKES Harapan Ibu, Jambi \\ *(hamdani@stikes-hi.ac.id)
}

\begin{abstract}
ABSTRAK
Kecelakaan kerja merupakan suatu rentetan kejadian atau suatu kecelakaan kerja yang terjadi karena akibat dari pekerja pada waktu melaksanakan pekerjaan dan juga disebabkan oleh adanya faktor-faktor atau potensi bahaya yang satu sama lain saling berkaitan. Desain penelitian menggunakan metode cross sectional dan jenis penelitian ini adalah penelitian kuantitatif. Populasi dalam penelitian ini adalah seluruh pekerja yang bekerja di bagian produksi di PT XY kabupaten bungo. Pengambilan sampel dilakukan dengan teknik proportional random sampling dan didapat jumlah sample sebanyak 58 responden. Proses pengumpulan data dilakukan dengan cara membagikan kuesioner kepada responden.Untuk menguji ada tidaknya keterkaitan umur, masa kerja dan unit kerja dengan kecelakaan kerja , peneliti menggunakan uji Chi-Square dengan P-value sebesar $<0,05$. Hasil penelitian antara variabel umur pekerja dengan kecelakaan kerja nmenunjukan P-value sebesar $(0,000$ $<0,05)$ yang menunjukkan adanya hubungan, variabel masa kerja dengan kecelakaan kerja menunjukkan P-value sebesar $(0,000<0,05)$ yang menunjukkan adanya hubungan, dan variabel unit kerja dengan kecelakaan kerja menunjukkan adanya P-value sebesar $(0,004<0,05)$ yang menunjukkan adanya hubungan dengan kecelakaan kerja. Mengadakan pelatihan untuk menambah wawasan dan skill bagi tenaga kerja serta pengawasan yang lebih intensif agar dapat meminimalisir dan menekan angka kecelakaan kerja.
\end{abstract}

Kata Kunci : Umur, masa kerja, unit kerja dan kecelakaan kerja

\section{ABSTRACT}

Work accident is an event or a series of accidents that occur as a result of the workers at the time of carrying out the work and also caused by other factors or potential hazards related to one another. The study design using cross sectional method and type of research is quantitative. The population in this study were all employees who worked in production at PT XY Bungo district. Sampling was done by proportional random sampling technique and obtained the number of sample were 58 respondents. The process of data collection is done by distributing questionnaires to examine whether there is linkage responden.Untuk age, length of service and the work unit with a work accident, investigators using Chi-Square test with a P-value of $<0.05$. The results between the variables age of workers with occupational accidents nmenunjukan $P$-value of $(0.000<0.05)$, which showed a link, variable working life with work accident showed P-value of $(0.000<0.05)$, which showed a link and variable unit with work accident showed P-value of $(0.004<0.05)$, which showed no association with workplace accidents. Providing training to increase knowledge and skills for the workforce as well as more intensive supervision in order to minimize and reduce the number of workplace accidents.

Keywords: Age, years of work units and accidents. 


\section{PENDAHULUAN}

Suatu perusahaan berkewajiban mengusahakan agar karyawan memiliki kesadaran turut dalam bertanggung jawab atas kelancaran, kemajuan, dan kelangsungan hidup perusahaaan. Di samping itu pemerintah bertanggung jawab menciptakan dan memelihara terbinanya hubungan yang serasi antara pengusaha dan karyawan, yang pada gilirannya akan mendorong terwujudnya kelancaran, efisiensi, dan kesinambungan perkembangan perusahaan, sekaligus dapat memenuhi kebutuhan kesejahteraan karyawan sesuai dengan perkembangan dan kemajuan perusahaan. ${ }^{1}$

Pada dasarnya kekuatan yang ada dalam suatu perusahaan terletak pada orangorang yang ada dalam perusahaan tersebut. Apabila tenaga kerja diperlakukan secara tepat dan sesuai dengan harkat dan martabatnya, perusahaan akan mencapai hasil yang sesuai dengan tujuan yang diinginkan oleh perusahaan. Dari uraian tersebut jelaslah bahwa faktor sumber daya manusia memegang peranan yang paling penting dan utama dalam proses produksi, karena alat produksi tidak akan berjalan tanpa dukungan dan keberadaan sumber daya manusia. ${ }^{2}$

Kecelakaan, hakekatnya merupakan kejadian tak terduga dan tidak diharapkan. Kecelakaan juga merupakan suatu kecelakaan yang berkaitan dengan hubungan kerja dengan perusahaan. Hubungan kerja disini berarti bahwa kecelakaan terjadi karena akibat dari pekerjaan atau pada waktu melaksanakan pekerjaan. Pada dasarnya, akibat dari peristiwa kecelakaan kerja dapat dilihat dari besar kecilnya biaya yang dikeluarkan bagi terjadinya peristiwa kecelakaan. ${ }^{3}$

Timbulnya kecelakaan kerja dipengaruhi oleh berbagai faktor diantaranya adalah faktor manusia atau pekerja dan faktor lingkungan. Faktor manusia memegang peranan penting didalam terjadinya kecelakaan kerja sedangkan dari segi lingkungan temperatur yang ada di tempat kerja dipercaya sebagai salah satu penyebab terjadinya kecelakaan kerja. $^{4}$
Penelitian menunjukkan, bahwa $85 \%$ sebab-sebab dari kecelakaan kecil bersumber pada faktor manusia. Dan selalu, apabila kita berbicara tentang manusia, persoalannya selalu rumit. Contohnya kecelakaan sebagai akibat emosi para pekerja seperti perkelahian antara sesama pekerja. Tanpa diduga-duga manusia kadang-kadang sengaja membuat kecelakaan, sehingga kata kecelakaan sudah tidak tepat lagi. Hal ini terjadi misalnya sebagai akibat kejenuhan, kebencian ataupun putus asa. ${ }^{5}$

Banyak jenis kecelakaan yang terjadi di tempat kerja dari yang ringan sampai dengan yang berat, tetapi hal ini tidak dilaporkan secara benar untuk ditindak lanjuti sebagai upaya pencegahannya. Pencegahan kecelakaan dapat dipelajari dari kecelakaan itu sendiri dan kecelakaan yang hampir terjadi. Dengan menginvestigasi setiap kejadian, kita bisa mengetahui tentang penyebab kecelakaan dan dapat menentukan langkah untuk pencegahannya atau memperkecil kemungkinan terjadinya kecelakaan. ${ }^{6}$

PT. XY yaitu pabrik yang bergerak dalam bidang pengolahan karet remah. Perusahaan ini berada di Kabupaten Bungo Provinsi Jambi, tepatnya dijalan lintas Sumatera KM-54 arah Padang. Dusun Sirih Sekapur Kecamatan Jujuhan Kabupaten Bungo. Perusahaan ini didirikan pada tahun 1989 dengan menempati area luas $\pm 143.000 \mathrm{~m}^{2}$. Jumlah pekerja yang bekerja di bagian produksi adalah sebanyak 147 orang, dimana di bagian inilah sering terjadi hal-hal yang tidak diinginkan serta merugikan para pekerjanya.

Dari uraian diatas maka penulis tertarik melakukan penelitian yang berjudul Faktor Manusia dan Faktor Pekerjaan yang Berhubungan Dengan Kecelakaan Kerja Pada Pekerja Di Bagian Produksi PT XY Kabupaten Bungo Tahun 2016.

\section{METODE}

Penelitian ini merupakan penelitian kuantitatif dengan desain penelitian cross sectional yang bertujuan untuk mengetahui gambaran pengetahuan, sikap dan peran keluarga dengan perilaku 
penerapan gizi seimbang pada lansia. Penelitian ini dilakukan di Puskesmas Tanjung Pinang Kota Jambi dimulai dari tanggal 06 sampai dengan 20 April Tahun 2016.

Populasi dalam penelitian ini adalah seluruh pekerja yang bekerja di bagian produksi PT XY tahun 2015. Pengambilan sampel dilakukan dengan proportional random sampling. Data dikumpulkan dengan cara menanyakan kepada responden yang dibantu dengan kuesioner. Hasil penelitian ini di analisis secara univariat dan bivariat dengan bantuan computer (Chi square-test).

\section{HASIL}

Berdasarkan hasil penelitian yang dilakukan didapatkan hasil dimana yang pernah mengalamai kecelakan kerja berjumlah $\quad 35$ responden $(60,3 \%)$. Sedangkan 23 responden $\quad(39,7 \%)$ dikategorikan tidak mengalamai kecelakaan kerja. (Tabel 4.2).

Berdasarkan hasil penelitian yang dilakukan didapatkan hasil dimana yang termasuk golongan umur muda berjumlah 35 responden (60,3\%), sedangkan 23 responden $(39,7 \%)$ dikategorikan kedalam golongan umur tua. (Tabel 4.3).

Berdasarkan hasil penelitian yang dilakukan didapatkan hasil dimana yang termasuk masa kerja baru $<6$ tahun berjumlah 23 responden $(39,7 \%)$. sedangkan 19 responden $(32,8 \%)$ di kategorikan kedalam masa kerja sedang 610 tahun dan 16 responden $(27,6 \%)$ di kategorikan masa kerja lama > 10 tahun . (Tabel 4.4).

Berdasarkan hasil penelitian yang dilakukan didapatkan hasil dimana yang termasuk unit produksi basah berjumlah 30 responden $(51,7 \%)$. sedangkan 28 responden $(48,3 \%)$ di kategorikan kedalam unit produksi kering. (Tabel 4.5).

Tabel 1

Analisa Univariat Umur Pekerja , Masa Kerja Dan Unit Pekerjaan Dengan Kecelakaan Kerja Pada Pekerja Di Bagian Produksi PT XY Kabupaten Bungo Tahun 2016

\begin{tabular}{lcc}
\hline \multicolumn{1}{l}{ Variabel } & $\mathrm{n}$ & $\%$ \\
KecelakaanKerja & & \\
Pernah & 35 & $60,3 \%$ \\
Tidak Pernah & 23 & $39,7 \%$ \\
Umur & & \\
Muda & 35 & $60,3 \%$ \\
Tua & 23 & $39,7 \%$ \\
Masa Kerja & & \\
Baru & 23 & $39,7 \%$ \\
Sedang & 19 & $32,8 \%$ \\
Lama & 16 & $27,6 \%$ \\
Unit Pekerjaan & & $51,7 \%$ \\
Unit Basah & 30 & $48,3 \%$ \\
Unit Kering & 28 & \\
\hline
\end{tabular}

Hasil distribusi frekuensi hubungan umur pekerja dengan kecelakaan kerja diketahui bahwa dari 35 yang berumur muda sebanyak 28 responden $(80,0 \%)$ yang mengalami kecelakan kerja. Sedangkan 23 responden yang berumur tua sebanyak 7

responden $(20,0 \%)$ yang mengalami kecelakaan kerja dan 16 responden $(60,6 \%)$ 
yang tidak mengalami kecelakaan kerja . (Tabel 4.6).

Hasil uji statistic diperoleh p-value ( $<<0,000)$. Hasil uji ini menunjukkan bahwa ada hubungan yang bermakna antara umur pekerja terhadap kecelakaan kerja PT XY kabupaten bungo tahun 2016.

Hasil distribusi frekuensi hubungan masa kerja dengan kecelakaan kerja diketahui bahwa dari 23 responden yang masa kerjanya baru < 6 tahun sebanyak 20 responden $(57,1 \%)$ yang mengalami pernah kecelakaan kerja. Dari 19 responden yang masa kerjanya 6-10 tahun sebanyak 11 responden $(31,4 \%)$ yang pernah mengalami kecelakaan kerja. Sedangkan dari 16 responden yang masa kerjanya $>10$ tahun sebanyak 4 responden $(11,4 \%)$ yang pernah mengalami kecelakaan kerja.. (Tabel 4.7).

Hasil uji statistic diperoleh $p$-value $(p<0,000)$. Hasil uji ini menunjukkan

bahwa ada hubungan yang bermakna antara masa kerja dnegan kecelakaan kerja pada pekerja di PT XY Kabupaten Bungo tahun 2016.

Hasil distribusi frekuensi hubungan unit pekerjaan dengan kecelakaan kerja diketahui bahwa dari 30 responden yang bekerja pada unit produksi basah sebanyak 23 responden $(68,6 \%)$ pernah mengalami kecelakaan kerja. Sedangkan dari 28 responden yang bekerja pada unit produksi kering sebanyak 11 responden $(31,4 \%)$ yang pernah mengalami kecelakaan kerja (Tabel 4.8).

Hasil uji statistic diperoleh $p$ value $(\mathrm{p}<0,004)$. Hasil uji ini menunnjukkan bahwa ada hubungan yang bermakna antara unit pekerjaan dengan kecelakaan kerja pada pekerja di PT XY kabupaten bungo tahun 2016.

Tabel 2

Analisa Bivariat Hubungan Umur Pekerja, Masa Kerja ,Unit Pekerjaan Dengan Kecelakaan Kerja Pada Pekerja Di Bagian Produksi PT XY Kabupaten Bungo Tahun 2016

Variabel

Kecelakaan Kerja

Total

\begin{tabular}{|c|c|c|c|c|c|c|c|}
\hline & \multicolumn{2}{|c|}{ Pernah } & \multicolumn{2}{|c|}{ Tidak Pernah } & \multirow{2}{*}{$\mathrm{n}$} & \multirow{2}{*}{$\%$} & \multirow{2}{*}{$\begin{array}{c}p- \\
\text { value }\end{array}$} \\
\hline & $\mathrm{n}$ & $\%$ & $\mathrm{n}$ & $\%$ & & & \\
\hline \multicolumn{8}{|l|}{ Umur Pekerja } \\
\hline Muda & 28 & 80,0 & 7 & 30,4 & 35 & 60,3 & 0,000 \\
\hline Tua & 7 & 20,0 & 16 & 60,6 & 23 & 39,7 & \\
\hline \multicolumn{8}{|l|}{ Masa Kerja } \\
\hline Baru & 20 & 57,1 & 3 & 13,0 & 23 & 39,7 & 0,000 \\
\hline Sedang & 11 & 31,4 & 8 & 34,8 & 19 & 32,8 & \\
\hline Lama & 4 & 11,4 & 12 & 52,2 & 16 & 27,6 & \\
\hline \multicolumn{8}{|l|}{ Unit Pekerjaan } \\
\hline Unit Basah & 24 & 68,6 & 6 & 26,1 & 30 & 51,7 & 0,004 \\
\hline Unit Kering & 11 & 31,4 & 17 & 73,9 & 528 & 48,3 & \\
\hline
\end{tabular}

\section{PEMBAHASAN}

Dari uraian kuesioner di ketahui umur responden yang berumur muda, dari hasil penelitian diketahui dari 35 responden dengan umur muda sebagian besar $(60,3 \%)$.

Hasil uji statistic diperoleh $p$-value $=0,000 \quad(p$-value $<0,05)$. Hasil uji ini menunjukkan bahwa ada hubungan yang 
bermakna antara umur dengan kecelakaan kerja pada pekerja di bagian produksi PT XY Kabupaten Bungo tahun 2016. Umur mempunyai pengaruh yang sangat penting terhadap kejadian kecelakaan kerja. Biasanya perusahaan mempekerjakan umur yang relatif muda dikarenakan tenaga mereka yang masih baru dan fresh serta dapat menekan biaya operasional karena belum memiliki pengalaman dibanding pekerja yang berpengalaman.

Menurut peneliti, banyak alasan mengapa tenaga kerja golongan umur muda mempunyai kecenderungan untuk menderita

kecelakaan kerja lebih tinggi dibanding golongan umur muda. Beberapa faktor yang mempengaruhi tingginya kejadian kecelakaan akibat kerja pada golongan umur muda anatara lain karena kurang perhatian, kurang disiplin, cenderung menuruti kata hati dan ceroboh dalam melakukan pekerjaannya.

Dari uraian kuesioner di ketahui masa kerja responden yang masa kerjanya baru yaitu < 6 tahun, dari hasil penelitian diketahui dari 23 responden dengan masa kerja baru $<6$ tahun sebagian besar $(39,7 \%)$.

Hasil uji statistik diperoleh p-value $=0,000 \quad(p$-value $<0,05)$. Hasil uji ini menunjukkan bahwa ada hubungan yang bermakna antara masa kerja dengan kecelakaan kerja pada pekerja di bagian produksi PT XY Kabupaten Bungo tahun 2016.

Masa kerja dapat diidentikkan dnegan pengalaman kerja. Artinya, pengalaman seseorang dapat mempengaruhi perilakunya dalam bekerja. Dengan demikian semakin lama kerja seseorang maka pengalaman yang didapat sewaktu bekerja semakin banyak yang memungkinkan bekerja lebih aman.

Dan rendahnya pengalaman serta keterampilan dan tenaga kerja baru biasanya belum mengetahui secara mendalam seluk-beluk pekerjaanya. Masa kerja merupakan faktor yang dapat mempengaruhi terjadinya kecelakaan kerja. Kewaspadaan terhadap kecelakaan kerja akibat bertambah baik sejalan dengan pertambahan usia dan lamanya kerja di tempat kerja yang bersangkutan.

Maka dari itu perlu adanya informasi oleh pihak perusahaan kepada para pekerja di bagian produksi, yaitu mengenai cara bekerja yang aman dan latihan-latihan praktek bagi tenaga kerja khususnya tenaga kerja yang masa kerjanya baru dalam keselamatan kerja agar menambah wawasan tentang $\mathrm{K} 3$ dan dapat terhindar dan menekan angka dari kecelakaan kerja.

Dari uraian kuesioner di ketahui unit pekerjaan di produksi basah dari hasil penelitian diketahui dari 30 ada 8 responden yang mengalamai kecelakaan kerja $(51,7 \%)$.

Hasil uji statistik diperoleh $p$-value $=0,004$. Hasil uji ini menunjukkan bahwa ada hubungan yang bermakna antara unit pekerjaan dengan kecelakaan kerja pada pekejrja di bagian produksi di PT XY Kabupaten Bungo tahun 2016.

Kecelakaan kerja yang terjadi di bagian produksi terutama paling banyak di temukan di unit basah. Menurut peneliti hal ini bisa terjadi karena pekerja pada bagian produksi di unit basah ini mempunyai proses kerja yang meruapakan proses utama dalam mengelola karet remah dan proses pengolahannya lebih banyak daripada unit pekerjaan lainnya. Misalnya pada saat pengolahan bahan baku di unit kering, suhu yang terdapat di tempat tersebut relatif panas dikarenakan penggunaan peralatan yang digunakan untuk mengolah bahan baku karet dan ventilasi yang kurang sehingga udara hanya terdapat di dalam lingkungan itu saja. Karyawan yang bekerja di lingkungan dengan suhu tinggi tidak menggunakan baju sambil bekerja dan berkipas kipas saat bekerja sehingga mengurangi kosentrasi saat bekerja. Dengan berkurangnya 
kosentrasi kerja, maka dapat menyebabkan kecelakaan kerja.

Di unit lain, yaitu unit produksi basah terjadi pengolahan produksi seperti bongkar muat bahan baku, memotong karet yang masih basah, pencucian bahan utama, pemotongan karet ke ukuran yang lebih kecil lagi, penggilingan bahan baku dan lain sebagainya. Dan pada saat proses produksi berlangsung, tenaga kerja menggunakan alat dalam mengolah bahan baku seperti pisau untuk pemotongan bahan baku dan alat-alat lainnya yang dapat menyebabkan kecelakaan kerja. Dan ditambah dengan kondisi lingkungan yang lembab karena adanya proses pencucian pada unit produksi ini sehingga lantai menjadi licin dan tenaga kerja mudah terpeleset dan tergelincir saat bekerja.

Maka dari itu upaya yang perlu dilakukan adalah pelakasanaan K3 diawali dengan cara mengenali hal-hal yang berpotensi menimbulkan kecelakaan kerja di perlukan dengan tujuan untuk mengurangi biaya perusahaan apabila timbul kecelakaan kerja. penglihatan dan sirkulasi udara di lingkungan kerja juga harus diperhatikan, dan pakaian pekerja sebaiknya juga tidak luput dari pengawasan dengan tidak menggunakan pakaian yang terlalu longgar atau terlalu sempit dan pentingnya menggunakan alat pelindung diri saat bekerja.

\section{DAFTAR PUSTAKA}

1. Oktarita, B. Yenny. Lestari, Anita. Hubungan Anatar Sikap Terhadap Penerapan Program K3 Dengan Komitmen Karywan Pada Perusahaan. 2001; Vol 10. No. 02.

2. Ibrahim, Jati K. Pelaksanaan Program Keselamatan Dan Kesehatan Kerja Karyawan PT. Bitratex Industries Semarang. Skripsi; 2010.

3. Tarwaka. Dasar - Dasar Keselamatan Kerja Serta Pencegahan Kecelakaan Di Tempat Kerja. Surakarta : Harapan Press; 2012.
4. Wibisono, Berhubungan
B. Faktor- Faktor dengan Kejadian

\section{KESIMPULAN}

Berdasarkan analisis hasil dan pembahasan dari penelitian yang dilakukan di PT XY Kabupaten Bungo Tahun 2016 didapat kesimpulan bahwa ada hubungan yang bermakna antara umur pekerja dengan kecelakaan kerja (p-value 0,000), ada hubungan yang bermakna antara masa kerja dengan kecelakaan kerja ( $p$-value $0,000)$, dan ada hubungan yang bermakna antara unit pekerjaan dengan kecelakaan kerja pada pekerja di bagian produksi PT XY Kabupaten Bungo ( $p$-value 0,004).

Diharapkan kepada pihak perusahaan mengadakan pelatihan kepada seluruh pekerja khususnya pekerja yang bekerja di bagian produksi dan segala golongan umur agar menambah wawasan pengetahuan mereka sehingga dapat terhindar dari kecelakaan kerja. pada unit kerja yang mempunyai risiko kecelakaan yang lebih besar seperti unit produksi basah perlu dilakukan pengawasan yang lebih intensif. Perlunya diberikan penghargaan kepada tenaga kerja yang menaati peraturan dan hukuman kepada pekerja yang tidak menaati peraturan kerja terutama peraturan K3. Selain itu perlunya pengawasan kepada seluruh pekerja yang sedang bekerja.

Kecelakaan Kerja pada Pekerja Tambang Pasir Gali di Desa Pegiringan Kabupaten Pemalang Tahun 2013. 2013; Vol 02. No. 08.

5. Anizar. Teknik Keselamatan Dan Kesehatan Kerja Di Industri. Yogyakarta : Graha Ilmu; 2009.

6. Sucipto, Cecep, D.Keselamatan Dan Kesehatan Kerja. Yogyakarta : Gosyen Publishing; 2014.

7. Isgiyanto, Awal. Teknik Pengambilan Sampel Pada Penelitian NonEksperimental. Jogjakarta: Mitra Cendikia Press; 2009. 
8. Ideputri, M.E dkk. Buku Ajar: Metodologi Penelitian Kesehatan. Yogyakarta : Nuha Medika; 2011.

9. Kadarwati, Rini. dkk. Beberapa Faktor Yang Berhubungan Dengan Kejadian Kecelakaan Kerja Di Pabrik Frame Kaca Mata PT. Luxindo Nusantara Semarang. Penelitian mahasiswa dan staf pengajar FKM UNIMUS. Juni 2005 - Juni 2006. Skripsi.

10. Pusphandani, M.E. Kesehatan Lingkungan Dan K3. Yogyakarta : Nuha Medika; 2013.

11. Saryono. Metode Penelitian Kuantitatif Dan Kualitatif Dalam Bidang Kesehatan. Yogyakarta : Nuha Medika; 2013. 